\title{
Genomics takes hold in Asia
}

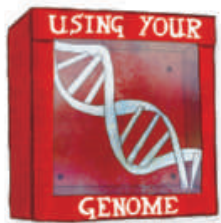
Recruited in 2001 from the US National Cancer Institute, Edison Liu was the first big international catch for Singapore's burgeoning Biopolis research hub. He still heads the Genome Institute of Singapore there and had the leading role in the Pan-Asian SNP Initiative, an effort to compare subtle genetic variations across Asian populations. He is currently chairman of Singapore's Health Sciences Authority and president of the Human Genome Organisation (HUGO). He spoke with Nature's David Cyranoski about how to make pan-Asian genomics research projects work.

\begin{abstract}
Collaborations among Asian scientists are just not as strong as those they share with scientists in the West. Why?

Scientists in Asia have a tendency to look past each other and focus on collaborations with the United States or Europe, partly because these collaborations get them more credit from their school administrations. Also, in Asia, most countries see each other as competitors. Just getting people together is an accomplishment.

About seven years ago we began talking about doing a genetics project in the AsiaPacific. It didn't gel for several reasons. The science itself wasn't mature. There was also a great disparity in capabilities and access to technologies between the various countries. There were also ethical concerns; some indigenous populations were worried about being told they were more likely to have certain diseases, and what that might mean for individuals within those populations.
\end{abstract}

\section{How did you get around that?}

We removed the negative connotations of disease and phenotype and just focused on how genetically different people were. Instead of looking at disease, we just found something that Asian scientists can work on together. Once we focused on diversity, all of a sudden countries such as Indonesia and the Philippines became very important because of the inherent diversity in their national populations. The infrastructure advantages of some countries such as Japan and Korea was evened out by the diversity that others offered.

\section{What were the results?}

We had data from 11 countries, 30 institutions and more than 73 ethnic groups. It was an interesting repainting of the migration history of Asia using autosomal markers. It confirmed some hypotheses, for example that genetic clustering was correlated with linguistic clusters. It also raised some questions. For example, our analyses suggested a common ancestral origin for all East and Southeast Asian

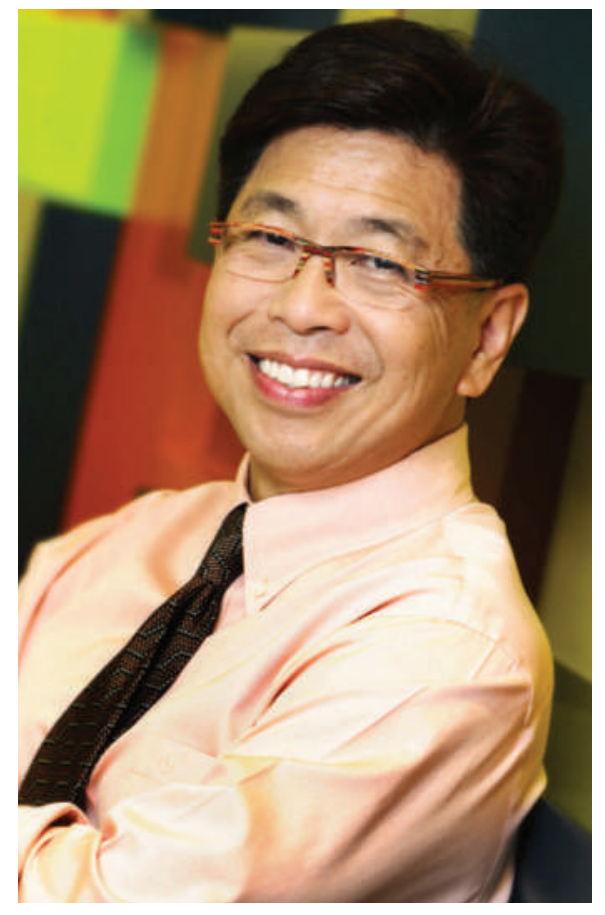

populations studied, implying that most of the gene pool in Asia came from a single initial entry of modern humans into the continent. The paper has now been submitted for publication.

Partly as a result of this, some countries have become more active in genetics. The Philippines health ministry is contemplating putting more resources into its genetics institute arm. The Eijkman Institute in Jakarta has begun to get more international funding. Twenty years ago, the only place recognized for genetics in Asia was Japan.

\section{After the heyday of $\mathbf{2 0 0 3}$ when the complete human genome was announced, HUGO dropped off the map. You have now moved its official base to Singapore. What do you hope to achieve?}

HUGO was ready for a re-look at its mission and goals. Much of the move of the HUGO office to Singapore was because of practical matters - for ease of administration.

However, part of the move was a recognition that the strongest chapter of HUGO was the Asia-Pacific. The core of scientific activity is more distributed now and is shifting eastwards.

There is also already talk of a phase II for our international SNP [single nucleotide polymorphism] initiative. For the current project we used 50,000-SNP microarrays from Affymetrix, which covered autosomal markers. Going forwards, we would like to use 500,000- or 1-million-SNP arrays. We could look at copy-number variation and haplotypes in the populations.

Now the first Asian genome has been sequenced (see page 60). The novelty and the timeliness of the catalogue of information makes it worthwhile. This is just the beginning of global efforts to sequence more human genomes so that we understand the range of diversity in our species. In the future, I would like to pursue a Pan-Asian genome project. Knowledge of this diversity is important as we try to match the best therapeutic drugs to specific world populations.

\section{What's next?}

I'd like to extend such a diversity study to Central Asia and across the Pacific Rim to some American Indian populations. With this breadth of coverage, the scientific community could really get a sense of the variability of the genome and how it has changed with migration. We could also start getting a genetic clock to go along with the anthropological ones that we have in mapping the history of humanity.

What value will this have for biomedicine?

Of course this will eventually help with clinical trials. We don't have the phenotypic data now, but as association studies get richer, certain genes will be linked to a drug response or drug toxicities. It is conceivable that with a map of human genetic diversity, health planners can project whether certain therapeutic drugs will be more or less appropriate for specific populations. See Editorial, page 1. 